\title{
La ruptura irónica del tiempo. Una confrontación entre Friedrich Schlegel y Nietzsche: A propósito del eterno retorno
}

\author{
AGUSTÍN MIRANDA CARRILLO \\ Universidad de Sevilla
}

\begin{abstract}
Zaratustra era amigo, en efecto, de todos aquellos que realizan largos viajes y no les gusta vivir sin peligros. ${ }^{1}$
\end{abstract}

1.

En ocasiones, son los mayores naufragios los que conducen a islas afortunadas. El primer combate nietzscheano contra la cultura se había saldado con un clamoroso fracaso. Nietzsche había quedado desprestigiado como filólogo y, al poco tiempo, parecía desertar de las filas de su propio ideario, renunciando a las expectativas depositadas anteriormente en la ópera wagneriana como obra de arte del futuro. Comenzaban los años de filósofo errante. Sin embargo, sería a través de esta larga travesía por el desierto de los falsos ídolos de juventud como comenzaría a despejar su más genuina respuesta a la gran crisis abierta en la modernidad por el anuncio de la muerte de Dios.

Este replanteamiento se conforma sobre la base de una nueva comprensión del nexo que liga a nihilismo, romanticismo y modernidad. ${ }^{2}$ Nietzsche a partir de la segunda Consideración intempestiva. De la utilidad y los inconvenientes de la historia para la vida, como bien expone Vercellone, retoma la cuestión del nihilismo, desde la línea inaugurada por la Frühromantik del movimiento pendular del desencanto y encantamiento de la apariencia, pero ahora en su reflexión se insiste aún más en el tema de la historicidad. Así es como, desde el concepto nietzscheano de la 'enfermedad histórica' se reproduce y se define

${ }^{1}$ Za, ed. A. Sánchez Pascual, Madrid: Alianza, 1998, p. 227.

${ }^{2}$ Federico Vercellone, en su artículo «Apariencia y desencanto. Nihilismo y hermenéutica en la Fruehromantik y en Nietzsche», Revista Occidente, 106 (1990), defiende que el debate en torno al nihilismo ya está presente en la atmósfera filosófica-cultural de la época de la Romantik, lo que favorece la conexión ineludible entre nihilismo, romanticismo y modernidad: «nihilismo, Romantik y modernidad constituyen, desde este punto de vista, un nexo indisoluble. Cada uno de sus componentes es un reenvío de otro en una prosecución infinita que esclarece su significado en el debate actual» ibid., p. 18. 
mejor el carácter artificial y fantasmagórico de la interioridad, debido a que «el excesivo dilatarse del conocimiento historiográfico hace imposible asimilar sus $\log r{ }^{3}{ }^{3}$.

Nietzsche busca pues, darle una nueva formulación al ideal formativo de armonía entre interior y exterior, lo que evidencia su proximidad a las tesis del primer romanticismo. Ello se observa con claridad en la diferencia que Nietzsche establece entre el individuo griego y el moderno. En el primero, en el griego, no se da la separación entre la interioridad y la exterioridad (cosa que tanto Schiller como Schlegel ya habían expuesto en sus escritos), ya que ésta es simplemente una proyección de aquélla, de manera que la armonía entre la interioridad y la exterioridad no es algo buscado, sino que ya se posee, y de ahí la ausencia de extrañamiento tanto a nivel interior como exterior. $\mathrm{Ni}$ el yo, ni el mundo, tienen que conquistar su identidad saliendo de sí, más bien al entrar en uno mismo se está habitando también el mundo, al mismo tiempo que saliendo al mundo se entra en uno mismo. Sin embargo se muestra que a pesar de los intentos modernos de superar la abstracción, en el individuo moderno se mantiene una clara separación -fruto no deseado del excesivo cultivo de un saber propio de «enciclopedias andantes» ${ }^{4}$, o en términos del joven Hegel de «erudición libresca»- entre su interioridad y su exterioridad.

Por consiguiente, el ser humano moderno que mediante el estudio de la historicidad aspira a hallar la identidad de la época moderna, paradójicamente, tal 'estudio-enfermiso' (enfermedad histórica) lo que trae consigo es, en primer lugar, la desconexión entre la historia y la vida, con lo que la historia se convierte en una actividad improductiva, que se muestra incapaz de reencantar el mundo, más aún, logra, dudoso honor, aumentar el desencanto del mundo de las apariencias, debido a que reproduce con exactitud la huida hacia otro mundo de la 'teo-teleología' de la fe cristiana. ${ }^{5} \mathrm{Y}$ en segundo lugar, la identidad moderna a pesar de que está repleta de conocimientos de otras épocas queda vacía de lo propio, o para ser más exactos, su ser propio se convierte en ser lo que no es, en ser lo histórico que ya no es pero que perdura como conceptos momificados en la modernidad, en no ser nada ahistórico: «pues los modernos no tenemos absolutamente nada propio; sólo llenándonos, con excesos, de épocas, costumbres, artes, filosofías, religiones y conocimientos ajenos llegamos a ser algo digno de atención, esto es, 'enciclopedias andantes', que es como nos calificaría

${ }^{3}$ Ibid., p. 32.

${ }^{4}$ SE, ed. J.B. Llinares, J. Muñoz y A. Sánchez Pascual, Madrid: Círculo de Lectores, p. 80.

${ }_{5}$ «El resultado de la cultura histórica, en su desarrollo incontrolado, es por tanto una actitud improductiva, una casi extrema retirada de la acción por parte del individuo para adoptar una actitud escéptica, desengañada. Paradójicamente, la cultura histórica se revela hija de esa fe cristiana que ha devaluado el mundo en nombre de la esperanza del más allá, reproduciendo con exactitud la estructura teo-teleológica de ésta: el rigor de la indagación produce una actitud desencantada, 'una existencia irónica'» Vercellone, F., op. cit., p. 33. 
tal vez un antiguo griego que se extraviase en nuestra época. Pues bien, en las enciclopedias todo su valor se circunscribe a lo que está en sus páginas, a su contenido, no a lo que está inscrito en la portada o es tapa y exterioridad; en consecuencia, toda la formación moderna es esencialmente interior: por fuera el encuadernador ha puesto algo así como «manual de formación interior para bárbaros exteriores» ${ }^{6}$.

Pero ya en Nietzsche comienza a dibujarse una nueva perspectiva en relación con esa propuesta pedagógica. Al realizar una exégesis de lo que Nietzsche denomina «manual de formación interior para bárbaros exteriores», no se excluye una lectura en la que se desvela el nihilismo inherente al pensamiento moderno, debido a que al igual que en la Frühromantik «la estetización del mundo coincide [...] con la pérdida de forma de una cultura» ${ }^{7}$, en Nietzsche al definir la verdadera cultura $(\text { Kultur })^{8}$ en la primera Consideración intempestiva. David Strauss, el confesor y el escritor, como «es ante todo la unidad de estilo artístico en todas las manifestaciones vitales de un pueblo» ${ }^{9}$, pone de manifiesto la necesidad de dar cabida a un 'gran estilo' capaz de abarcar el espíritu de la auténtica cultura, al mismo tiempo que exilia la 'cultería' ${ }^{10}$ del panorama alemán de la época. De manera que, tanto en la Frühromantik como en Nietzsche, es la ausencia de una forma cultural capaz de configurar una identidad propia de la época (la caída del clasicismo en el primer caso, y la falta de un 'gran estilo' en el segundo) lo que desencadena el nihilismo. E incluso se puede afirmar, y aquí ya no se está siguiendo la lectura de Vercellone, que el alejamiento del clasicismo por parte de Schlegel, junto con la progresiva importancia que éste le otorga a la ironía y a la poesía universal progresiva (poesía romántica) como modo de llevar a cabo la obra de arte total, es decir, el eterno retorno de lo diferente, es similar al anticristianismo de Nietzsche en su concepción del

${ }^{6} \mathrm{SE}$ p. 80. En este texto, el autor continúa insistiendo en la escisión radical presente en el individuo moderno entre interioridad y exterioridad, insiste en la paradoja de la modernidad en la que ninguna época histórica se había logrado un individuo tan rico interiormente y a la vez tan vacío, nunca una interioridad tan llena se había desvelado tan vacía de contenido asumido y vivido como propio, e incluso Nietzsche llega a afirmar que este carácter de lo moderno es más bárbaro que el de los pueblos llamados incultos: 'este contraste de dentro y fuera da a lo exterior un carácter aún más bárbaro del que necesariamente tendría en el caso de un pueblo inculto que sólo se desarrollase a sí mismo conforme a sus groseras necesidades» ibid.

${ }^{7}$ Vercellone, F., op. cit., p. 34.

${ }^{8}$ Nietzsche opone la auténtica cultura a la 'cultura' que se da en la época y que denomina 'cultería' (Gebildetheit), siendo sus representantes los 'cultifilisteos' (Bildungsphilister), los cuales confunden la victoria militar sobre Francia con una victoria cultural, con lo que se convierte en unos bárbaros que divinizan lo mediocre de la vida cotidiana y convierte en imposible el proyecto de construcción de una cultura alemana propia.

${ }^{9}$ DS, ed. A. Sánchez Pascual, Madrid: Alianza, 1988, p. 30.

${ }_{10}$ «Cuando se acepta como regla lo chabacano, lo trillado, lo fofo, vulgar y cuando aparece como expresión excitante lo malo y lo corrompido, entonces cae en descrédito lo vigoroso, lo no vulgar, lo bello» ibid. p. 127. 
eterno retorno que le lleva a un nihilismo activo capaz, no de hacer frente, sino de mirar de frente la conversión del mundo en fábula.

Es a partir de la segunda de las Consideraciones intempestivas, cuando esta carencia de forma deja de ser entendida por Nietzsche como nueva negatividad que anuncia la llegada del nihilismo, y se convierte en lo que posibilita la construcción de una nueva forma que ya no se deja acotar por principios universales trascendentes, o dicho en términos de Schlegel, ya no se deja acotar por un arte clásico de la representación. Esta nueva forma lleva incorporada dentro de sí la pluralidad y la apertura que hace que nunca pueda considerársela como definitiva ni acabada ${ }^{11}$.

Tras el ensayo Sobre el estudio de la poesía griega (1797), que cierra su etapa clasicista, el joven Friedrich Schlegel ${ }^{12}$ mantiene la poesía como elemento imprescindible de análisis de la sociedad y como respuesta a la crisis de la modernidad, mientras que, por otro lado, la ironía aparece como uno de los conceptos fundamentales sobre el que ha de girar su programa de formación (Bildung), alternativo al ideal de progreso ilustrado. A ella se unirá el desarrollo del programa de una nueva mitología. El puente que le permite pasar del clasicismo al romanticismo, está construido a partir de los pilares del 'fragmento', lo 'paradójico', el Witz y la 'reflexión', siendo esta última una reinterpretación del concepto fichteano (tal y como sostiene Paul De Man en El concepto de ironía $)^{13}$.

A partir de 1797, con los Fragmentos del Lyceum, el autor irá insistiendo cada vez más en la idea de que la descripción de los antagonismos entre la poesía griega y la moderna ha de realizarse desde un discurso marcadamente moderno, dada la imposibilidad y la inconveniencia del traslado de los ideales de la antigüedad a la modernidad. Ésta ha iniciado un itinerario nuevo que no necesita una Edad de oro como modelo: «no se debería invocar nunca el espíritu de la Antigüedad como una autoridad» ${ }^{14}$.

${ }^{11}$ Ernst Behler, en diversos artículos, insiste en la conexión entre el primer romanticismo, en especial Schlegel, y en Nietzsche (fundamentalmente el de Sobre verdad y mentiras en sentido extramoral), aunque colocando especialmente el acento en la cuestión del análisis del lenguaje, lo que lleva implícito una teoría del concepto y de la verdad como metáforas y, por tanto, la estrecha relación entre filosofía y poesía. Behler, E., «Tradizione romantica e decostruzione nella filosofia del linguaggio del giovane Nietzsche», en Campioni, Giuliano - Venturelli, Aldo (ed.), La biblioteca ideale di Nietzsche, Napoles: Guida, 1992 (especialmente pp. 106, 111, 112).

${ }^{12}$ Convencionalmente, el período de juventud del pensamiento schlegeliano suele extenderse hasta la época de su conversión al catolicismo en 1808.

${ }^{13}$ De Man, P., El concepto de ironía, tr. M. Asensi y M. Richart, Valencia: Episteme, 1985, pp. 10-13.

${ }^{14}$ Schlegel, F., Kritische Ausgabe, ed. E. Behler, J.J. Anstett y H. Eichner, Paderborn: 
Por su parte, la ironía en Schlegel se convierte en el puente -no retóricoentre la filosofía (que busca el conocimiento) y la poesía (que busca la belleza), abriendo así la posibilidad de un conocimiento poético del mundo que no caiga en la 'monotonía de la prosa' propia de una razón instrumental. Así, la ironía pasa a ser la forma de asumir la fragmentación y la escisión moderna sin salirse de ellas, sino aprendiendo a pensarlas poéticamente desde ellas mismas, sin lanzar vías de escape hacia un ideal exento de fragmentaciones y escisiones: «la filosofía es la auténtica patria de la ironía, la cual podríamos definirla como belleza lógica: pues donde quiera que se filosofa [...] se debe ofrecer y exigir ironía. [...] Únicamente la poesía puede alzarse también desde este aspecto hasta la altura de la filosofía, y no se apoya, como la retórica en retazos irónicos» ${ }^{15}$.

La ironía adquiere un carácter fronterizo que se transforma en el pensamiento del guerrero que posee en un brazo el arma de la poesía y en el otro el de la filosofía ${ }^{16}$. Con estas armas la ironía osa enfrentarse a la problemática realidad del mundo, asumiendo desde el principio que se tiene perdida la guerra en la que poder izar la bandera de la victoria sobre la cambiante realidad, pero a pesar de ello no se renuncia a ganar alguna batalla a través de las obras, artísticas por supuesto, que aunque son siempre incompletas, también siempre dicen algo sobre el ser humano, su obrar, y sobre el mundo (triple ámbito de acción), al modo de lo incomprensible y de la parodia, claro está, pero es que «la ironía es la forma de lo paradójico. Paradójico es todo aquello que es a la vez bueno y grande» ${ }^{17}$.

Pero, ¿por qué el lenguaje de la ironía es incomprensible y paradójico? Pues bien, es incomprensible porque como Schlegel mantiene en su artículo Sobre la incomprensibilidad (1800), una vez realizada una clasificación de los diferentes tipos de ironías (ironía en bruto, ironía fina y cultivada, la superfina, la sincera, la dramática, la doble, y finalmente la ironía de la ironía $)^{18}$, asumir que toda la realidad ha de estar a merced de un entendimiento absoluto que haga posible la comprensibilidad total del mundo sería el final del ser humano, debido a que la incomprensibilidad es, al igual que en Nietzsche («cuán lamentable, cuán sombrío y caduco, cuán inútil y arbitrario es el aspecto que

Schöning, 35 vols., 1958ss., vol. I, p. 242 (de ahora en adelante se citará con la sigla KFS seguida del número de volumen, en romano, y del número de página en arábico). Hay traducción en castellano en Schlegel, F., Poesía y filosofía, ed. D. Sánchez Meca y A. Rábade Obradó, Madrid: Alianza, 1994, p. 53.

${ }^{15}$ KSF I 242 (Schlegel, F., Poesía y filosofía, pp. 52-53. El subrayado es mío).

${ }^{16}$ «poesía y filosofía son un todo indivisible, eternamente vinculadas, aunque rara vez juntas [...]. Entre ambas se reparten el supremo territorio de cuanto hay de grande y sublime en la humanidad» Schlegel, F., Über die Philosophie (1799): KSF II 178 (Poesía y filosofía, p. 83).

${ }^{17}$ KSF I 243 (Poesía y filosofía, p. 54).

${ }^{18}$ Schlegel, F.: Sobre la incomprensibilidad, en Vv.Aa., Antología de los primeros años del romanticismo alemán, tr. K. Braum y M.A. Seijoó (edición bilingüe), Salamanca, 1994, pp. 
tiene el intelecto humano dentro de la naturaleza; hubo eternidades en las que no existió; cuando de nuevo se haya acabado, no habrá sucedido nada. Pues no hay para ese intelecto ninguna misión ulterior que conduzca más allá de la vida humana» ${ }^{19}$ ), inherente al mundo y al ser humano. Ese fondo incomprensible hay que dejarlo en la oscuridad (al modo de lo que Hölderlin denomina el logos atético en el que se muestra al ocultarse -fondo apofánticola naturaleza), para no quebrantar el sosiego humano con la prepotente llamada del entendimiento que lo quiere des-cubrir todo, que quiere desencantar el mundo, olvidando que también él -el entendimiento- es un cantar, un contar, un modo -entre otros- de acceder al mundo y, que tiene su origen, en lo caótico y en lo incomprensible: «lo más delicioso que tiene el hombre, el propio sosiego interior pende, finalmente como cada uno puede fácilmente saber, en algún lugar de un punto que debe ser dejado en la oscuridad, en cambio también soporta y mantiene el todo y perdería esta fuerza en el mismo momento que se lo diluyera en entendimiento. Verdaderamente tendría miedo, si el mundo entero, que es lo que vosotros exigís, fuera por una vez en serio comprensible totalmente. $\mathrm{Y}$ acaso ¿no se ha formado este mundo infinito por medio del entendimiento partiendo de la incomprensibilidad y del caos?» ${ }^{20}$

Es precisamente esta necesidad de la incomprensibilidad la que torna en paradójica la ironía, ya que como afirma el propio Schlegel: «la parodia es realmente la potencia misma; la ironía es meramente el equivalente del deber ir al infinito» ${ }^{21}$.

La ironía es la tendencia al infinito y la parodia es la manifestación finita de la ironía. La parodia es pues, la presencia de lo que no puede ser presentado (la ironía) pero sí presentido (anhelado paradójicamente) al mismo tiempo que cumplido, aunque nunca de modo pleno, deseado constantemente e incomprensiblemente, ya que se sigue presentando a pesar de su impresentabilidad inherente a sí misma, siendo precisamente su permanente impresentabilidad (paradoja precisión) la muestra inequívoca de su existencia.

Con las credenciales de la incomprensibilidad y de lo paradójico la ironía hace muy difícil su admisión en el ámbito de lo unívocamente definible. Hace vana la empresa de apresarla en las redes del entendimiento. Pero es que precisamente la ironía surge para escapar de la prisión de la coherencia que objetiva lo infinito en conceptos trasparentes por los que se describe el mundo, y en los que nada queda de éste, salvo -poca salvación es ésta- un sistema de fantasmagorías que ahuyenta fuera de sí lo que no puede comprender, gritando entonces despectivamente su irracionalidad y exiliándolo hacia lo innecesario ${ }^{22}$.

\section{5-217.}

${ }^{19}$ VM, ed. J.Llinares, Madrid: Círculo de lectores, 1996, p. 37.

${ }^{20}$ Schlegel, F., op. cit., p. 219.

${ }^{21}$ KFS XVIII 218.

${ }^{22}$ «La ironía es indefinible en razón de la no posibilidad de hallar un punto exterior al 
Por consiguiente, la ironía se muestra a través de su pluralidad de definiciones como una sobreabundancia que no puede ser contenida en ninguna de sus determinaciones, a la vez que asume -siempre parcialmentecada una de ellas, con lo que traspasa los límites del conocimiento objetivo ('entendimiento cosificador'), siendo su característica esencial este continuo proceso pendular que va desde el decir de la incomprensión a la incomprensión de su decir, desde la finitud de lo infinito a la infinitud de lo finito, desde lo que es sin poder ser a lo que sin poder ser es, desde la materialidad de la forma a la forma de la materialidad.

Los primeros extremos de este movimiento pendular es lo que Benjamin denomina -refiriéndose a la concepción de la ironía schlegeliana- ironía material, mientras que los extremos opuestos, pero siempre conectados a través del movimiento irónico, es nombrado como ironía formal. De esta manera, el movimiento de la ironía cuando tiene su mayor fuerza en la materia de la obra artística (ironía material) queda caracterizado como negativo, subjetivo y «descansa en una reflexión subjetiva, lúdica, del autor» ${ }^{23}$, trayendo consigo la destrucción de la materia, que es lo que Hegel llama la muerte del arte (el exceso de lo representado - lo absoluto- en el arte romántico acaba destruyendo la forma artística que se muestra incapaz de contenerlo). Aquí el artista se siente insatisfecho ante la obra porque quiere expresar la infinitud con los materiales de la finitud, con lo que el 'fracaso' queda anunciado por la propia reflexión crítica del autor sobre su obra. ${ }^{24}$

La tragedia del héroe romántico moderno, que para Schlegel está encarnada perfectamente en el personaje de Hamlet, es precisamente que la guerra está perdida desde el principio, ya que el absoluto siempre escapa a la representación porque es un 'im-presentable', o lo que es lo mismo, la guerra es interminable, lo que sería el final (la rendición) para cualquier ser finito clásico que buscara la tranquilidad en la armonía libre de escisiones. Pero su condición de héroe le hace no renunciar a la batalla, no renunciar a la creación artística, no renunciar a ese eterno retorno de lo diferente que es la conquista de la obra de arte total. $\mathrm{Y}$ es este no querer renunciar el que permite que el individuo romántico sea

objeto poético, y, además, porque en la misma obra de Schlegel la ironía sufre un vaivén de definiciones que la muestra al final como mero significante. De ello se sostiene que aquí la ironía no se teoriza sino que se practica: hay una ironía de la ironía» Asensi, M., La teoría fragmentaria del círculo de Iena: Friedrich Schlegel, Valencia: Pre-Textos, 1991, pp. 60-62.

${ }^{23}$ Benjamin, W., El concepto de crítica de arte en el romanticismo alemán, tr. J.F. Yvars y Vicente Jarque, Barcelona: Península, 1998, p. 126.

${ }^{24}$ Diego Sánchez Meca distingue la ironía schlegeliana de la socrática a partir de las diferentes valoraciones que se dan en cada una de ellas respecto a la relación entre necesidad y libertad. Así, en la ironía schlegeliana -a diferencia de la socrática- tiene lugar una oposición irresoluble entre «el mundo condicionado de la naturaleza y el mundo incondicionado de la libertad, y, por tanto, la libertad-necesidad de una mediación entre ambos. Que esta mediación 
calificado como guerrero, héroe, artista (¿cómo Übermensch?), en lugar de fracasado, debido a que considera que la guerra es el batallar de cada día, mientras que la paz es sólo la parálisis que contenta únicamente a espíritus satisfechos que creen haber conquistado la fantasmagoría de una impoluta armonía, o a espíritus enlutados, que se baten en retirada melancólica ante el ejército de escisiones que crecen en el campo de batalla de la modernidad.

Por consiguiente, el batallar irónico del héroe romántico se caracteriza, como ya se ha comentado, por una continua destrucción y creación de la obra ('campo de batalla estético') que refleja el proceso de auto-destrucción y autocreación del yo, o lo que es lo mismo, un proceso de disolución y de (in)genio (Witz: «sociabilidad lógica» ${ }^{25}$ ) del artista. Por este motivo, aquí no hay lugar para un arte imitativo, debido a que no existe nada acabado, completo y absoluto que pueda ser presentado como la representación de una realidad objetivada y cosificada, sino que todo está, merced a la ironía, en continuo proceso de destrucción ('sensibilidad negativa') ${ }^{26}$ y construcción ('sensibilidad positiva' o 'gracia' -Anmut- $)^{27}$. Por ello, el arte tiene que ser necesariamente un arte en y de proceso, un arte de devenir, ya que tiene como imperativo estético el deber de ir al infinito (similar al imperativo nietzscheano de que «la vida debe inspirar confianza $»^{28}$ ). Así, el arte -al igual que ocurría con la ética formal kantiana- se convierte en un arte más formal que material, en el que cobra primacía la forma que se desea representar (lo absoluto) sobre lo representado materialmente (siempre será relativo y finito), y esto, no lo olvidemos, no es ya voluntad del artista -a diferencia de la autonomía moral kantiana-, ni si quiera del genio, sino del propio proceder del arte, del arte romántico, de la poesía romántica: «la poesía romántica [al igual que Nietzsche sostiene respecto a la vida] es una poesía universal progresiva. [...] La poesía todavía está en devenir; sí, esa es precisamente su esencia, que está siempre en un perpetuo cambio, que nunca puede ser terminada. No puede ser agotada por ninguna teoría» ${ }^{29}$.

En el mundo todavía encantado de la verdad romántica se busca la liberación de las escisiones, pero paradójicamente se muestra que la escisión

sea inalcanzable es la paradoja de la ironía» Schlegel, F., Poesía y filosofía, p. 63, nota 20.

${ }^{25}$ KSF I 243 (Poesía y filosofía, p. 55).

${ }^{26}$ «Hay una sensibilidad negativa, que es mucho mejor que nada, pero mucho más rara. Se puede amar algo fervorosamente justamente porque no se posee [...]. Lo mismo que el eros platónico, esta sensibilidad negativa es, pues, hija del exceso y la pobreza. [...] El signo distintivo [...] es tener siempre que querer sin poder jamás, querer siempre oír sin percibir jamás» KSF I 244 (Poesía y filosofía, p. 57).

${ }^{27}$ «La gracia [Anmut] es vida correcta; sensibilidad que se contempla y se construye a sí misma» KSF I 240 (Poesía y filosofía, p. 50).

${ }^{28}$ KSA XIII 17[3]. Hay traducción castellana en: Izquierdo A. (ed.), Friedrich Nietzsche: Estética y teoría de las artes, Madrid: Tecnos, 2004, p. 75.

${ }^{29}$ Schlegel, F., Athenäum, en Antología de los primeros años del romanticismo alemán. pp. 
es connatural a lo humano, y que toda síntesis, toda armonía, si es verdadera armonía con y en el mundo, ha de ser también división, ocultamiento, noche, pluralidad, individualidad, continua creatividad con, desde y por la escisión: «la poesía romántica no compite para conquistar una verdad última e inamovible, sino que se propone como experiencia paradójica de la verdad abierta a la dimensión imaginaria de lo posible. En lugar, pues, de esforzarse por eliminar o someter las contradicciones o las antinomias, moviliza la fuerza noética de la fantasía para percibir la unión de lo visible y lo invisible, de lo pensable y de lo que no puede ser pensado. El romanticismo aparece entonces como perspectiva de un pensamiento que renuncia al poder, al nomos, remitiendo todo polemos, todo conflicto, al juego de la diferencia. Un juego que une lo no unificable, pero que no lo concilia en una síntesis última y que no existe unión que no sea también división, disensión, polemos en cuanto proceso mismo de transformación y transfiguración del mundo ${ }^{30}$.

Por ello el romántico si tuviera que elegir -en el caso de que ello fuera posible- entre hallar una armonía que hipoteca el 'encantamiento' de lo humano, y el encontrarse con lo humano en toda su pluralidad a costa de perder la armonía, se inclina por lo segundo, y ahí estará la escisión permanente para recordarle su 'decisión', para recordarle que, a pesar del clásico refrán tradicional alemán, en la noche no todas las vacas son pardas.

Es así como la ironía abre un horizonte hermenéutico libre de nostalgias y de ideales dogmáticos, donde el pensar nunca se cierra a la corrección, y la praxis siempre está guiada por la búsqueda de nuevas experiencias que le acercan al absoluto, a la absoluta finitud de la acción humana, al absoluto carácter perdurable de lo intempestivo de lo moderno. Por consiguiente, el ser humano moderno, su acción y su búsqueda, desde la propuesta de Schlegel, han de entenderse como permanentemente intempestivos, ya que lo moderno queda caracterizado siempre como inacabado a la vez que necesario, como ilimitada limitación que humaniza la acción y los ideales del ser humano, debido a que la realidad del ideal humano es la continua búsqueda que no obtiene la recompensa del triunfo, que no obtiene una satisfacción de lo deseado que traería consigo la aniquilación del deseo. Más bien lo que se pretende es la absolutización del deseo, el no permitir que el deseo se agote en lo deseado, el sustituir una visión teleológica por una que sea capaz de valorar cada instante por sí mismo, sabiéndose que ningún instante será plenamente satisfactorio, pero sabiéndose también que esa insatisfacción del instante incita a emprender la búsqueda de un nuevo momento que convierte en intempestivo el anterior y en moderno el presente, modernidad que está condenada a la vez que liberada a ser diacrónicamente intempestiva, a ser un eterno retorno del

54-55.

${ }^{30}$ Sánchez Meca, D., Metamorfosis y confines de la individualidad, Madrid: Tecnos, 1995, 
anhelo de absoluto.

El convertir en perdurable el carácter intempestivo de la modernidad se hace desde la renuncia al dogmatismo, desde lo inaceptable de la existencia de una acción que conlleve la armonía y la plenitud al ser humano (estamos en el tercer ámbito de análisis: en el antropológico, después de haber expuesto el estético y el hermenéutico), ya que la experiencia ha enseñado al hombre moderno descrito por Schlegel que el creerse en posesión de la plenitud, o de un planteamiento capaz de alcanzarla, trae consigo el equipaje de la alienación, de la esclavitud del continuo presente por un futuro siempre esperado pero nunca alcanzado, del sometimiento del ser humano a una idea fruto de la iluminación humana que deshumaniza al individuo y lo convierte en un mero contenedor de los residuos ideales de humanidad. El ser humano experimentado, pero no por ello tan maduro que ya no sea capaz de ilusionarse (sin iluminarse) por las nuevas experiencias que el correr del tiempo trae consigo, ya que no ha vivido ninguna experiencia como definitiva, es un ser que hace de la hermenéutica su sombra, que hace de la hermenéutica su inacabada esencia, único modo de otorgarle a su ser el carácter de inacabado, de intempestivo, de perdurable en su devenir.

El individuo moderno, constructor y destructor de sí mismo y de sus acciones, descrito desde una perspectiva hermenéutica, no espera descifrar el enigma del sentido de su vida, ni mucho menos de la vida de sus semejantes, sino que se ilusiona con el necesario cuestionamiento de sus acciones, de sus obras, en pos de un absoluto al que aspira pero sabe que es inalcanzable, y que además ha de ser así, para poder ser una persona capaz de desear, capaz de sentir la escisión de su ser que le hace ser, de sentir la fragmentación que le otorga la posibilidad de buscar la totalidad de los fragmentos que lo unifica con el mundo fragmentado y escindido de la modernidad, único modo de ser uno con el todo, único modo en que la ironía romántica tiene para aspirar al en kai pan lessingiano, de desear la comunión con la naturaleza sin perder la personalidad y superando así por saturación, que no por suturación (este es el proyecto 'clásico-idealista'), la permanente escisión que muestra la aporía pre-romántica.

La infinitud no puede ser cosificada en una obra, así que únicamente en el constante obrar del proceso creativo se puede captar -nunca definitivamentela totalidad fragmentaria que se desea representar, únicamente en la necesidad de la representación, no en la representación misma, queda representada la infinitud, ya que el pretender representar la infinitud es ya un proceso infinito, porque la infinitud no puede ser representada.

De esta manera, la teoría estética romántica schlegeliana se convierte en una representación sobre la propia representación, en una forma, no ya de un contenido finito concreto, sino sobre la forma misma, la cual no es nada 'formal' por lo que no se presenta ella misma, en cambio, con ello se pone de 
manifiesto la 'presencia' de la 'informalidad de la forma', y esto es la esencia del arte romántico, la muerte del arte clásico, y el nacimiento del arte moderno por excelencia. Se pone así el punto final, o para ser más exacto los puntos suspensivos, a cualquier concepción de la obra como algo cerrado, completo y definitivo: «todo escrito, toda obra, pues, ha de asumir su inacabamiento esencial, comprenderse como proyecto o fragmento de futuro que no vale sino como perspectiva de lo que en ella queda siempre inacabado, única forma apropiada de un proceso de individuación concebido como algo eternamente en devenir, y donde el sistema o la totalidad no es la suma ni la síntesis, sino la copresencia de la pluralidad de las partes en cuanto copresencia de todo a sí mismo [modelo orgánico en posición al modelo mecanicista]. [...] Realiza, en definitiva, un modo de realización entre lo particular y lo universal en el que la verdad no es alcanzable por la vía lineal, solitaria y conclusiva de la demostración, sino en virtud de un proceso abierto, colectivo e indefinido de intercambio, de diálogo, de mezcla» ${ }^{31}$.

Ello no conlleva la renuncia a la búsqueda de lo infinito, de la obra de arte total, sino más bien, convierte en modelo de lo romántico el aspirar a una totalidad que no se puede hallar definitivamente, pero también constatando la imposibilidad de renunciar a ese deseo, siempre insatisfecho de modo completo, a pesar del progresivo acercamiento a la infinitud. Se acepta así el abismo existente entre la realidad de la finitud humana y la posibilidad del deseo, entre el conflicto de lo que se tiene y de a lo que se aspira, todo ello expuesto a través de la 'categoría' de fragmento donde se expresa el conflicto y la contradicción: «todo fragmento, todo libro que no se contradice a sí mismo es incompleto» ${ }^{32}$.

Se produce de este modo, la dialéctica constitutiva de todo ser humano, debido a que al no tratarse de un ser armónico y completo, sino escindido entre lo que se tiene y lo que se quiere, la praxis pone de manifiesto - tanto en la obra, como en la interioridad de lo humano- una 'destrucción constructiva' y una 'construcción destructiva' que van formando progresivamente al individuo, a la vez que autolimitándolo, y lo traslada más allá de los límites del presente, acercándolo a los nuevos umbrales del futuro: «no se sabe apreciar el valor y la dignidad de la autolimitación, que es, sin embargo, para el artista como

p. 135.

${ }^{31}$ Diego Sánchez Meca en el estudio introductorio a los escritos de Friedrich Schlegel (Fragmentos del Lyceum [1797], Sobre la filosofía [1799], Diálogo sobre la poesía [1800] e Ideas [1800]) recogidos bajo el título de Poesía y filosofía, pp. 21-22.

${ }^{32}$ KFS XVIII 83. Este planteamiento guarda un paralelismo directo con el teorema de Gödel, según el cual es imposible encontrar un sistema completo y consistente al mismo tiempo, ya que si es completo es contradictorio y si es consistente entonces es incompleto. De esta manera, Gödel traslada la argumentación no sólo al fragmento y al libro, sino también a cualquier sistema. Parafraseando a Schlegel podemos decir, con Gödel, que todo sistema que 
para el ser humano en general, lo primero y lo último, lo más necesario y lo más elevado. Lo más necesario, porque donde quiera que no se limita uno así mismo se ve uno limitado por el mundo, con lo que se convierte en un esclavo. Lo más elevado, porque uno sólo se puede limitar a sí mismo en los puntos y en los aspectos que posee fuerza infinita, creación y destrucción de sí mismo [esto es lo que denomina Schlegel sensibilidad ${ }^{33}$ ] ${ }^{34}$. Esta necesidad de la destrucción, y de la posterior construcción, como juego de contrarios que hace posible la actividad humana, está también presente en Nietzsche: «lo creado debe ser destruido, para hacer sitio a lo creado de nuevo; la posibilidad de las valoraciones depende de su capacidad de ser negadas. El creador tiene que ser siempre un destructor. La valoración misma, sin embargo, no puede ser destruida: eso es la vida» ${ }^{35}$.

Por ello, quien actúa, quien valora, no es la identidad del yo, sino la pluralidad de yoes que habitan en el reduccionista concepto del yo, y que a pesar de ser esa pluralidad una limitación sin límite renuncia a quedar apresada por una de sus limitaciones, ya que este yo-plural anhela lo que nunca puede llegar a ser: lo infinito. Se trata de un moderno Proteo comprometido con cada una de sus 'máscaras' (etimología griega de persona, lo que más tarde le servirá a Nietzsche para afirmar que: «todo lo que es profundo ama la máscara» ${ }^{36}$ ) pero no identificado permanentemente con ninguna de ellas, siendo su esencia el continuo devenir de una máscara a otra en busca de una liberación siempre alcanzada, pero nunca consumada, mostrando su irónica historia el rostro siempre cambiante de la modernidad, pero reconocible precisamente en la novela - constituida ahora como nueva mitología- que narra su constante evolución, sus aventuras a través de lo que no es, pero que le otorgan su serdevenir. Es la exploración del 'país' de lo posible la que hace que el poeta romántico (sujeto por excelencia de un yo plural) no sea capaz, ni quiera, dar unas señas verdaderas y estables de su ser. El poeta se convierte así en una especie de «inquilino» del «albergue del ser» ${ }^{37}$, único hábitat que le permite ser en su devenir, que le posibilita ser un ermitaño que se hace siendo en la no permanencia en una delimitación de su ser.

no se contradice a sí mismo es incompleto.

33 «Sensibilidad [Sinn] (para un arte, una ciencia, una persona [Mensch] concreta, etc.) es espíritu dividido, autolimitación, o sea, un resultado de la creación y la destrucción de sí mismo» KFS I 240 (Poesía y filosofía, p. 50).

${ }^{34}$ KFS I 241 (Poesía y filosofía, p. 51).

${ }^{35} \mathrm{KSA}$, noviembre de 1882-febrero de 1883, 5[1] (Friedrich Nietzsche: Estética y teoría de las artes, p. 65).

${ }^{36}$ MBM, ed. A. Sánchez Pascual, Madrid: Alianza, 1985, p. 65.

37 «Mas lo hace justamente para extraer de ello la fuerza que permita al ser humano afirmarse en esa condición abismática como en su casa -aunque de hecho no exista hogar, no exista Centralwesen, sólo la posibilidad de construir, habitar, pensar hogares, crear albergues en medio del camino, dado que ahora 'die Mitte ist überall' [...], el centro está en todas partes-. O, por decirlo de otra forma: ya no hay periferia como lugar de desecho y olvido, salvo para la mentalidad nihilista que añora sus pasados dominios...» Barrios, M., La voluntad de poder 
3.

En el pensamiento nietzscheano del eterno retorno se quiere insistir en la importancia del devenir, en la renuncia a que éste quede aniquilado por el estatismo de los conceptos filosóficos que inmovilizan el continuo movimiento del tiempo, que convierten -en terminología nietzscheana- en «momias conceptuales» ${ }^{38}$ a las filosofías que examinan la vida. Vida entendida como devenir, no como un ir y venir de lo que ya es, no como un mero puente que hay que cruzar para que al lograr alcanzar lo que se busca -guiado por una visión teleológica del tiempo- merezca la pena la vida que se ha hipotecado para conseguirlo, sino un ir haciendo y siendo en el continuo movimiento del devenir que es la vida, que no se hipoteca porque la propia vida no puede ser 'utilizada' por otra persona, o para ser más exactos, la propia vida -al igual que dice Heidegger de la muerte- sólo puede ser vivida por uno mismo y por nadie más.

En la filosofía de Schlegel se aspira al absoluto, al infinito: «La ironía es meramente el equivalente del deber ir al infinito» ${ }^{39}$. Pero se constata que tal tarea está condenada al fracaso, ya que el absoluto no puede ser mostrado por el ser humano en sus obras, debido a que tanto éstas como el ser humano son limitados. Por ello, lo único que le queda al romántico es un acercamiento asintótico a dicho absoluto, e incluso, para que no caiga en el olvido la imposibilidad de aprehender el absoluto, se insiste una y otra vez en la finitud, en la insuficiencia de toda obra singular, en la insuficiencia de toda visión particular del yo, e incluso en la insuficiencia de toda argumentación que tenga por objetivo ser definitiva y, de ahí, la importancia que Schlegel concede al fragmento. Así, la actividad del romántico se caracteriza por la búsqueda de la obra de arte total, de manera que el proceso creativo se convierte en interminable porque el romántico nunca queda plenamente satisfecho con sus creaciones. He ahí el eterno retorno (el proceso creativo es interminable y no puede dejar de emprenderse constantemente), el comenzar una y otra vez el proceso creativo que se dirige hacia un absoluto que se sabe inalcanzable a la vez que irrenunciable, y he ahí también, el hecho de que tal eterno retorno lo sea de lo diferente, de las diferentes obras de arte ‘paridas’ por el alma romántica y preñadas de un futuro que aunque abortado en cada obra singular, crece en la idea de la obra de arte total. El ansia de infinitud del artista romántico nunca puede quedar satisfecha con los resultados limitados de sus obras finitas, siempre tiene que continuar con el proceso creativo ('eterno retorno': absoluto diacrónico) que da lugar a una obra diferente de las anteriores ('de lo diferente') que logren 'satisfacer', siempre parcialmente, su deseo inalienable e inalcanzable de infinitud.

como amor, Barcelona: Serbal, 1990, p. 159.

38 «Todo lo que los filósofos han venido manejando desde hace milenios fueron momias conceptuales; de sus manos no salió vivo nada real. [...] ¡Ser filósofo, ser momia, representar el monótono-teísmo con una mímica de sepulturero!» CI, ed. A. Sánchez Pascual, Madrid: Alianza, 1980, pp. 45-46. 
En definitiva, se trata pues, de que el artista romántico proyecta su deseo de infinitud en las obras de arte que crea, sin embargo tal deseo, como ya se ha dicho, nunca puede ser consumado porque la forma del absoluto no puede quedar apresada en la materialidad finita del arte, aunque ello no le impide continuar con su obrar artístico. Es precisamente esa no parálisis creativa, la que posibilita hablar de un eterno retorno en Schlegel, un iniciar y finalizar una obra de arte para volver a construir y destruir otra obra de arte, y así sucesivamente, que es lo que se conoce en la filosofía del joven Schlegel como el proceso de autoconstrucción y autodestrucción del yo, de la obra de arte y de la verdad: «Schlegel parte terminológicamente de la ironía socrática, y no interpreta su 'autoempequeñecerse' de manera mayéutico-comunicativa, como Schleiermacher, sino en forma metafísica, como modestia ante el absoluto inalcanzable, y a la vez como distanciamiento crítico respecto de sí mismo y de los contrincantes del diálogo, esto es, la ironía como manifestación de la verdad» ${ }^{40}$.

Tal eterno retorno, la interminabilidad del proceso creativo, lo es de lo diferente porque lo que se repite no es la misma obra, sino el deseo de infinitud, siempre insatisfecho, que está presente en cada una de las diferentes obras singulares del artista, convirtiéndose tal deseo, gracias a la labor de la crítica del arte, en la obra de arte total del romántico, en lo que Benjamín denomina en El concepto de crítica de arte en el romanticismo alemán, ironía formal ${ }^{41}$ (constructiva y que no depende de la voluntad del artista, lo que no alcanza a vislumbrar Hegel, quizás debido al exceso de miras especulativas unido a la miopía estética del pensador de la Fenomenología del espíritu), que nace a partir de las cenizas de la ironía material ${ }^{42}$ (destructiva y que depende de la voluntad del artista, lo que Hegel en sus Lecciones sobre la estética llamará muerte del arte, o para ser más exactos «el arte como cosa acabada»).

Es pues, sobre las ruinas (muerte del arte representativo), producidas por la aplicación de la ironía a la materia y a la forma de la obra de arte singular, donde se edifica la obra de arte total, que es el lugar indestructible por excelencia de la manifestación de la infinitud como finalidad del arte romántico, y también

${ }^{39}$ KFS XVIII 218.

${ }^{40}$ Kramer, H., Platón y los fundamentos de la metafísica, tr. Á. Capelletti y A. Rosales, Caracas: Monte Ávila, 1996, p. 326.

${ }^{41}$ «La ironización de la forma le ataca [a la obra de arte] sin destruirla [...]. Este procedimiento muestra una llamativa afinidad con la crítica, que, seria e irrevocablemente, disuelve la forma para transfigurar la obra singular en obra de arte absoluta, para romantizarla. [...] En esta clase de ironía, que nace de la relación con lo incondicionado, no se trata de subjetivismo ni de juego, sino de la asimilación de la obra limitada al absoluto, de su plena objetivación al precio de su ruina. Esta es la forma de la ironía propia del espíritu del arte, no de la voluntad del poeta» Benjamin, W., op. cit. pp. 124-125.

${ }^{42}$ «Por tanto, el arbitrio del verdadero poeta tiene su espacio sólo en la materia y, en la medida en que actúa consciente y lúdicamente, se convierte en ironía. Esta es la ironía subjetivista. Su espíritu es el autor que se eleva sobre la materialidad de la obra en tanto que la desprecia» 
es el lugar objetivo construido en todo proceso creativo por la praxis irónica. Es necesario, pues, destruir la materia artística, la forma singular de la obra. En definitiva, es preciso acabar con el arte como representación de una idea singular, para poder construir la obra de arte total sobre la que se manifiesta el absoluto inexpresable, incomprensible y paradójico. Este es el momento de mayor positividad y objetividad en el arte, momento en el que el yo del autor queda disuelto en su propia obra, y su voluntad deja de ser el motor del desarrollo dialéctico del arte (entre el autor y su obra conectados entre sí, y cada uno de ellos -el autor y la obra- relacionados consigo mismo), para convertirse en sujeto del placer estético ante la contemplación de la obra de arte total, siempre haciéndose y nunca hecha porque su esencia es su constante devenir, dé-venir, ha de venir, su ser es lo que es no siendo, de ahí que el ansia de manifestar el absoluto nunca puede quedar satisfecha plenamente.

Por consiguiente, todo lo realizado por el ser humano, al ser éste finito, es calificado como provisional, y ésta es su gran limitación. Pero al mismo tiempo, en el objeto creado hay una 'promesa' de infinitud, no tanto en el resultado de lo hecho, sino en el origen del proceso creativo, ya que éste tiende a la infinitud, aunque no por ello el individuo deja de ser consciente de la imposibilidad de tal proyecto. El artista romántico encarna de este modo la definición nietzscheana de ser humano: «el hombre es el único animal capaz de prometer». Consigue -a pesar de constatar que lo que siempre queda es el constante devenir y que ninguna obra particular puede satisfacerle- prometer y prometerse que no renunciará a la acción, que nunca dejará de crear obras de arte. Y es entonces cuando esta promesa pasa a ser considerada como la obra de arte total que da sentido a su vida y al mundo, se convierte en una promesa que precisamente al no cumplirse completamente en ninguna acción concreta se cumple diacrónicamente en su incumplimiento sincrónico. Se cumple porque el devenir no es detenido, no es aniquilado por la prepotencia de plenitud de una obra singular, se cumple, en definitiva, porque asume que a pesar del eterno devenir promete que nunca dejará de mejorarlo sin necesidad de detenerlo, ya que es el propio eterno retorno del devenir el que hace al artista romántico ser lo que es, el que le hace decir sí a la vida, sí al eterno retorno de lo diferente, que aunque no satisface sincrónicamente su deseo de infinitud, sí lo hace diacrónicamente en su insaciable actividad artística. Tal actividad artística es descrita por el propio Nietzsche en los siguientes términos: «el devenir, sentido e interpretado desde el interior, sería la creación constante de alguien satisfecho, inmensamente rico, infinitamente tenso y oprimido, de un Dios que sólo se sobrepone a la tortura del ser a través de la metamorfosis y del cambio constante: la apariencia, su redención transitoria alcanzada en cada instante; el mundo como la sucesión de visiones y redenciones divinas en la apariencia. [...] El arte desde la experiencia del artista, del músico, sobre todo: la tortura del deber crear, como instinto dionisíaco» ${ }^{43}$.

Benjamin, W., op. cit. p. 123.

Estudios Nietzsche, 5 (2005), ISSN: 1578-6676, pp. 101-128 
Ahora bien, ¿de dónde obtiene el héroe romántico la fuerza necesaria para emprender la tarea del acercamiento a un absoluto que se sabe inalcanzable? $\mathrm{o}$, trasladando el problema al ámbito nietzscheano, se transforma en el siguiente: ¿de dónde saca la fuerza el nietzscheano para vivir y actuar en un mundo sin dioses? ${ }^{44}$ En el caso de Schlegel, una primera respuesta puede ser que tal

${ }^{43}$ KSA XII 2[11] (Friedrich Nietzsche: Estética y teoría de las artes, p. 72).

${ }^{44}$ En Nietzsche, la fuerza que el ser humano necesita para vivir en un mundo sin dioses, lo que lleva aparejado su conversión en 'sobrehumano' (Übermensch), la obtiene al menos desde tres ámbitos, que no se excluyen sino que pueden ser incluso complementarios. El primer ámbito, o primera respuesta a la cuestión planteada, se encuentra en la segunda de las consideraciones intempestivas. Aquí, Nietzsche sostiene que si una persona cuando está enamorada no se atreve a realizar algo que siempre ha deseado hacer, entonces nunca lo hará: «Imagínese a un hombre al que arrebata una violenta pasión por una mujer o por una gran concepción; ¡ cómo cambia su mundo! [...] lo que capta, en fin, nunca lo captó de forma más verdadera [...]. Todas sus valoraciones están cambiadas y desvalorizadas [...]. Y, sin embargo, este estado-absolutamente ahistórico, antihistórico- es la matriz, no ya de una acción injusta, sino de todas las acciones justas; y ningún artista logrará su creación, ningún jefe militar su victoria, ningún pueblo su libertad, sin haberla antes deseado y anhelado en tal estado ahistórico. [...] Así, todo agente ama su acción infinitamente más de lo que ella merece ser amada: y las mejores acciones se llevan a cabo en un arrebato de amor tal que, desde luego, no valen este amor, por incalculable que, por lo demás, sea su valor» KSA I 253 (UPH pp. 61-62). Así pues, el amor se convierte en el motor de la acción humana, en la fuerza creativa que el ser humano posee para actuar en y sobre el mundo. La segunda y la tercera respuestas, se encuentran en La voluntad de poder. En el aforismo 802 se sostiene -en línea con lo expuesto en la segunda intempestiva- que el recuerdo del amor posee el poder necesario para dar lugar a que el ser humano pueda ejercer una fuerza creadora artística capaz de proyectarla en el mundo: «El amor [...] aquella embriaguez se aparta de la realidad de tal modo que, en la conciencia del amante la causa desaparece, creyéndose que puede encontrarse cualquier otra cosa en vez de ella [...]. El amor [...] una fiebre que tiene motivos para transfigurarse, una embriaguez que hace bien en mentir sobre sí misma... $\mathrm{Y}$ en todo caso se miente bien cuando se ama, se miente bien y ante sí y a propósito de sí; nos presentamos ante nosotros mismos transfigurados, más fuertes, más ricos, más perfectos, somos más perfectos... Aquí encontramos el arte como función orgánica; le encontramos inscrito sobre el angélico instinto 'amor'; le encontramos como el mayor estimulante vivo; el arte tiene, por tanto, una finalidad sublime aún en su propia mentira... Pero nos engañaríamos si nos ajustásemos a su fuerza creadora; hace más que imaginar simplemente; llega a desplazar los valores: No sólo desplaza el sentimiento de los valores; el que ama, vale más, es más fuerte. [...] Su economía general se convierte en algo más rico que nunca, más poderoso, más completo que en el hombre que no ama. El que ama se prodiga: se siente rico para serlo» KSA XIII 299-300: 14[120], primavera 1888 (VP, tr. A. Froufe, Madrid: Edaf, 1990, §802, pp. 436-437). Por último, en el aforismo 848 de «La voluntad de poder como arte» se afirma que: «la vida debe inspirar confianza. [...] Para cumplirlo, el hombre debe ser ya por naturaleza embustero, debe ser artista ante todo», de manera que este 'imperativo vital' es el que hace que el ser humano se convierta en un artista de su existencia, en un creador de invenciones, en un arquitecto de metáforas en el que pone en juego su propia vida en el mundo, en el que la pluralidad de perspectivas sobre el mundo crea nuevos mundos nouménicos posibles del y desde el mundo de la vida (Lebenswelt) sobre el mundo fenoménico presente en el que se desarrolla la vida, y donde: «el amor, el entusiasmo, 'Dios', son simples refinamientos del extraño engaño de sí mismo, simples seducciones para la vida, simples creencias en la vida. En el momento en que el hombre se sintió engañado, en que se ha embaucado a sí mismo, en que cree en la vida, ¡Qué sentimiento 
fuerza proviene del deseo irrenunciable que posee el ser humano a aspirar a la infinitud, a pesar de que su conciencia ponga de manifiesto que tal deseo es imposible de satisfacer, y el propio romántico acepte el designio de la conciencia. Esto significa que su actividad se inicia a sabiendas de la incompleción final del resultado, de que el absoluto es inalcanzable. De hecho, la llave que pone en marcha el motor de su acción es más bien el reconocimiento de la 'docta ignorancia' -o 'escepticismo agnóstico’ en términos de Krämer, o ‘conciencia crítica de la limitación’ según Diego Sánchez Meca-, de la imposibilidad de alcanzar la meta en dicha tarea, de atrapar y expresar el absoluto.

Pero, ¿de dónde viene ese irrenunciable anhelo de absoluto? El pensamiento romántico no deja de historizar dicho anhelo, situando la modernidad como etapa de transición ${ }^{45}$. Considera que, en un primer momento, el seguidor de la religión católica tiene la ilusión de alcanzar el absoluto en la otra vida, donde el Dios creador del mundo espera reunirse con sus buenas criaturas que no han sucumbido a la tentación del mal presente en el mundo y del que Dios es totalmente inocente (objetivo del proyecto de la teodicea leibniziana). En un segundo momento, el ilustrado, en un proceso histórico de «profanación» de la teología judeo-cristiana, y dirigido por el optimismo de la idea de progreso, busca el «reino de Dios en la tierra», y éste es el sentido de la Historia Universal que se expone en la filosofía de la historia donde el mal del presente queda positivado en la esperanza de alcanzar el bien de la humanidad en el desarrollo de la historia. Y por último, el romántico -centrándonos en el caso del joven Schlegel- ya no espera encontrarse con el absoluto, pero busca en el futuro (el

de poderío! ¡Qué triunfo de artista hay en el sentimiento de poderío! ¡El hombre ha llegado a ser nuevamente dueño de la 'materia', dueño de la 'verdad'...! Y cualquiera que sea el momento en que se alegre, siempre es igual en su gozo; se alegra como artista, goza como poder, goza con la mentira como con una nueva facultad» KSA XIII 521: 17[3], mayo-junio 1888 (VP §848: «El arte en 'el origen de la tragedia'», p. 462). Resulta paradójico que un pensador como Nietzsche, aparentemente tan antiplatónico y antikantiano, recurra a la hora de explicitar el origen de la acción humana a dos planteamientos cercanos a la filosofía platónica y a la kantiana como son respectivamente la anámnesis (VP §802, KSA XIII 299-300: 14[120], primavera 1888) y el ‘imperativo categórico' (VP §848, KSA XIII 521: 17[3], mayo-junio 1888).

45 «La modernidad es para los románticos, una época intermedia situada, como segundo momento dialéctico de la historia del mundo, entre el 'ya no' de la Antigüedad, perfecta en su armonía con la naturaleza, y el 'todavía no' de un advenimiento utópico del reino de Dios, presentido como futuro inaccesible a nuestra determinación. En esta comprensión se conserva el principio básico del clasicismo, que ve en la Antigüedad el acontecimiento único y perfecto de la armonía entre hombre y naturaleza [éste es el caso de Schiller en las Cartas sobre la educación estética del hombre], pero integrado en la visión herderiana del proceso histórico de la cultura que entiende este primer período como infancia paradisíaca de la humanidad, imposible de volver a reproducir en el presente. En comparación con esta primera época perfecta, la época presente, la modernidad, se caracteriza por la negatividad propia de su condición de antítesis, es decir, por ser una época no natural sino espiritual, la época de la fragmentación, de la pura tendencia, dominio del entendimiento y de la crítica, mientras que el futuro se imagina como la posible realización de la síntesis entre lo antiguo y lo moderno, lo natural y lo espiritual» Sáchez 
ideal ya no está en el pasado -como sí ocurría en el clasicismo-) un acercamiento asintótico al absoluto del que no puede ni quiere liberarse (proyecto de la ironía romántica), porque este proceso es precisamente el que le da sentido y libertad a su vida, ese proceso es la historia de su vida, es su vida, e incluso quizás ese proceso en el que se narra la relación del ser humano con el absoluto acabe finalmente por convertirse en el absoluto mismo tan ansiado, se pase del deseo de absoluto a la absolutización del deseo, del simulacro de la actividad artística como muestra de infinitud al simulacro del absoluto como necesidad de la actividad artística ${ }^{46}$.

No obstante, aquí nos decantamos por una segunda respuesta a la cuestión planteada. Tal respuesta es la siguiente: el deseo irrenunciable que el ser humano -cuando menos, este es el caso del romántico- tiene de absoluto se debe a la disarmonía presente en el individuo entre la imaginación y el entendimiento, es decir, a la disarmonía entre lo que es capaz de entender -que siempre es limitado- y lo que es capaz de imaginar-que no tiene límites-. La capacidad de imaginar que posee el ser humano es lo que da lugar a que no se conforme con los estrechos límites de lo que es capaz de entender, de lo que es capaz de traer a su presencia y de convertirlo -en términos de Heidegger- en ser-a-la-mano, ya que su imaginación proyecta al ser humano desde el presente de la presencia al futuro de la ausencia intuida como posibilidad para un nuevo presente que está por venir, que está en dé-venir. Tal disarmonía entre la imaginación y el entendimiento es lo que Kant define en su Crítica del juicio como sublime; sin embargo el sentimiento de sublime en Kant trae consigo en un primer momento dolor, pero después éste da lugar a un sentimiento de placer $^{47}$, mientras que en el romántico tal disarmonía puede llegar a producir angustia (Sehnsucht), dolor por el que aparentemente no parece vislumbrase un placer futuro ¿Por qué? Para Kant lo sublime se produce, en el caso de lo sublime dinámico,

Meca, D., «Friedrich Schlegel y la ironía romántica», Er. Revista de Filosofía, 26, 85-86.

${ }^{46}$ ¿Y en la actualidad qué queda de esa relación entre la finitud humana y la infinitud del absoluto? El creyente no vuelve de la otra vida -si alguna vez estuvo en ella- para contarnos lo que allí encontró. La mayoría de los ilustrados se han cansado de esperar el reino de Dios en la tierra. Y qué decir de los románticos. Los que no se han suicidado, han terminado perdiéndose en el corazón de las tinieblas, o han abandonado su condición de románticos y se han aburguesado en el abismo, cometiendo el grave error de olvidar que: «quien con monstruos lucha cuide de no convertirse a su vez en monstruo. Cuando miras largo tiempo a un abismo, también éste mira dentro de ti» MBM p. 106.

${ }^{47}$ Francois Lyotard califica este placer fruto del sentimiento de lo sublime kantiano como doble: «Pero este dolor engendra a su vez un placer y un placer doble: la impotencia de la imaginación atestigua, por el contrario, que intenta hacer ver incluso lo que no puede ser visto y así, pretende armonizar su objeto con el de la razón; por otra parte, las insuficiencias de las imágenes es un signo negativo de la inmensidad del poder de las Ideas. Este desajuste entre las facultades da lugar a un extrema tensión (la agitación, dice) que caracteriza el pathos de lo sublime, a diferencia del apacible sentimiento de lo bello [en lo bello tiene lugar una armonía entre la imaginación y el entendimiento]» Lyotard, F., «Lo sublime y la vanguardia», Vv.Aa., 
ante la contemplación de un objeto concreto, de algo limitado, definible -por ejemplo una tempestad sobre el océano-, y entonces, y después de un momento de asombro doloroso, el ser humano siente 'como si' el mundo hubiese sido creado para él, porque es capaz de ir más allá de su entendimiento y disfrutar con una tempestad que ya no puede quedar contenida en una definición fruto de una razón científico-técnica, porque la imaginación le ha añadido un plus no cuantificable racionalmente, produciendo todo ello un sentimiento de placer en el individuo, una «armónica disarmonía» en el descanso del guerrero que es capaz de contemplar de manera satisfactoria el objeto concreto que logra alcanzar y que le produce el sentimiento de lo sublime.

En cambio, para el romántico la disarmonía no se da a la hora de contemplar un objeto concreto, ni limitado, ni definible, sino en relación con el infinito, de manera que es incapaz de alcanzarlo, de «traerlo» a su presencia para contemplarlo -como sí ocurre en el caso de la tempestad-, y de ahí que no pueda obtener la recompensa de una satisfacción permanente, de un sentimiento de placer que le haga ser uno con el mundo, sino más bien lo que consigue es un estado permanente de insatisfacción, una angustia por no conseguir traer a su presencia el infinito al que aspira, por encontrarse cara a cara con el nihilismo (término que emplea el propio Schlegel en 1797, antes incluso que Jacobi) ${ }^{48}$.

4.

En la filosofía de Nietzsche el 'gran anhelo' ya no se expresa como aspiración a un absoluto desprovisto de una insuperable carga de historicidad. El hombre loco, en nombre de La gaya ciencia ('ciencia jocosa'), anuncia la muerte de Dios, transforma radicalmente la ya histórica relación que el ser humano mantiene con el absoluto: «lo más santo y poderoso que ha habido en el mundo se ha desangrado bajo nuestros cuchillos. ¿Quién nos limpiará de esta sangre? ¿Con qué agua podremos limpiarnos? ¿Qué fiestas expiatorias, qué juegos sagrados tendremos que inventar? La grandeza de este acto, ¿no es demasiado grande para nosotros? ¿No hemos de convertirnos nosotros mismos en dioses para aparecer dignos de él? ¡Jamás ha habido acto más grande y todos los que nazcan después de nosotros pertenecerán por obra de este acto a una historia más grande que toda historia hasta ahora habitada! $\gg^{49}$

Nietzsche responde a estas preguntas con la posibilidad del eterno retorno de lo idéntico, este es el 'agua' que nos limpia la sangre divina, esta es la fiesta expiatoria, el juego sagrado, ¿también la forma de convertirnos en dioses?

La cuestión que Nietzsche se plantea en el eterno retorno es la del 'pensamiento más abismal', aquel que una vez asumido en toda su amplitud se

Pensar el presente, Madrid: Cuadernos del Círculo de Bellas Artes, 1992, p. 24.

${ }^{48}$ KSF XVIII 27, 573 y 575, Philosophische Lehrjahre. 
transforma en El peso más pesado, en la decisión en la que el individuo tiene que estar a una distancia suficiente de su propia vida -al igual que con la ironía romántica se establece una distancia entre el sujeto y su obra- como para poder ponerla toda en juego: «suponiendo que un día, o una noche, un demonio te siguiera en la más solitaria de tus soledades y te dijera: «Esta vida, tal y como la has vivido y estás viviendo, la tendrás que vivir otra vez, otras infinitas veces; y no habrá en ella nada nuevo, sino que cada dolor y cada placer y cada pensamiento y suspiro y todo lo indeciblemente pequeño y grande de tu vida te llegará de nuevo, y todo en el mismo orden de sucesión. [...]» ¿No te arrojarías al suelo rechinando los dientes y maldiciendo al demonio que así te habló? O has experimentado alguna vez un instante tremendo en el que le contestarías: «jeres un dios y jamás he oído decir nada tan divino!» Si esa noción llegara a dominarte, te transformaría y tal vez te aplastaría tal y como eres. ¡La pregunta ante todas las cosas: «¿quieres eso otra vez y aún infinitas veces?» pesaría como

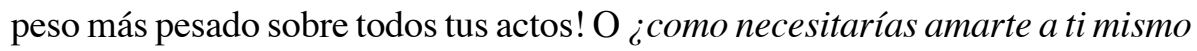
y a la vida, para no desear nada más que esta última y eterna confirmación y ratificación? $\gg^{50}$

Como se observa, el que dice sí al eterno retorno nietzscheano ha tenido previamente que experimentar un instante en su vida lo suficientemente valioso, lo suficientemente sublime como para haber merecido la pena haber nacido -a pesar de los sufrimientos que ha vivido y los que aún están por venir-, para así ser capaz de aceptar todos los instantes de su vida y convertirlos en valiosos en sí mismos, en fines en sí mismos, no en medio para un fin futuro. De esta manera, aunque sea por un instante ha vivido, salvando las distancias, la consigna idealista de hallar 'el reino de Dios en la tierra', de ahí que no desee ninguna trascendencia, ninguna vida futura, sino la pura inmanencia de su vida que rehusa teleologizarla, ésta es su fidelidad a la tierra, su fidelidad al devenir de la vida, su amor a sí mismo y a la vida.

En Nietzsche, a diferencia del Fausto de Goethe, no se está proponiendo vender el alma al diablo para lograr alcanzar un instante en el que se logre estar satisfecho con uno mismo ${ }^{51}$. No se dice sí al eterno retorno para abrir la posibilidad de hallar en el futuro un instante sublime en el que el ser humano se sienta satisfecho de sí mismo y de su vida, no se busca el instante sublime a posteriori,

${ }^{49} \mathrm{GC}$ §125: «El hombre loco, p. 161.

${ }^{50}$ GC § 341: «El peso más pesado», p. 250. El subrayado es mío.

51 «FAUSTO: ¿Qué podrás dar tú, pobre diablo? ¿Pudo jamás ninguno de los tuyos comprender a un espíritu de hombre en su sublime anhelo? [...]. MEFISTÓFELES: Semejante encarguito no me arredra, que puedo servirte esos tesoros. Pero, mi buen amigo, también llega después un tiempo en que deseamos paladear algo bueno con todo descanso. FAUSTO: ¡Si alguna vez llego a reposar satisfecho en blanca cama, deje yo de existir en el acto! ¡Si logras lisonjearme, trapacero, con la idea de que podré yo alguna vez estar contento de mí mismo, si con el deleite puedes engañarme, sea ese para mí el último día de mi vida! ¡Te brindo la apuesta! MEFISTÓFELES: ¡Acepto!» Goethe, J.W., Fausto, en Obras Completas, tr. R. Cansinos 
sino que tal instante es formalmente a priori (no a nivel de contenido, ya que se quiere remarcar la incondicionalidad del sí a la vida), es decir, lo sublime ya se ha experimentado en el pasado -en este sentido es a priori- y de ello se obtiene la confianza necesaria en la vida para decir sí a la eterna repetición de ésta, para no desear más que «esta última y eterna confirmación y ratificación» -en este sentido es formal. Tal ratificación y confirmación de la vida lo es de toda ella, de cada instante particular de la misma que tiene su propio valor en sí mismo, en su pura inmanencia en la que se renuncia a la trascendencia -al igual que Schlegel renuncia, a diferencia del clasicismo, a la posibilidad de la creación de una obra de arte definitiva y perfecta-, esta es la forma de ser fiel a uno mismo, siéndole fiel a la tierra. Al absolutizar cada instante de la vida finita repetida eternamente en su identidad se está 'sublimando' no sólo el deseo de infinitud del ser humano en otra vida, sino también se «excluye toda perspectiva de salvación; la historia no tiene fin y por eso no podemos salvarnos en ella» ${ }^{52}$. El ser humano metamorfosea de este modo su vida en un 'absoluto sincrónico' que no hipoteca ningún instante en particular por ningún absoluto futuro (ya sea en otra vida, crítica a la teleología cristiana, o en esta vida, crítica a la idea de progreso), no se aprehende ningún absoluto inalcanzable (al igual que en Schlegel), sino el instante sublime experimentado para convertir en absoluto cada instante ('absoluto sincrónico') de la vida particular de una persona, amando incluso el destino que está por venir, amando el devenir (el interminable proceso creativo de las diferentes obras artísticas en el caso de Schlegel) y todo lo que éste traiga consigo, como se pone de manifiesto fundamentalmente en la tercera parte de Así habló Zaratustra, aunque también en la cuarta parte: «- ¿habéis querido alguna ocasión dos veces una sola vez, habéis dicho en alguna ocasión ‘¡Tú me agradas, felicidad! ¡Sus! ¡Instantes!?’ ¡Entonces quisisteis que todo vuelva! - Todo de nuevo, todo eterno, todo encadenado, trabado, enamorado, oh, entonces amasteis el mundo. - Vosotros eternos, amadlo eternamente y para siempre: y también al dolor decidle: ¡Pasa, pero vuelve! Pues todo placer quiere ¡Eternidad!»53

En el capítulo «De la visión y el enigma» de la tercera parte de Zaratustra, se insiste una vez más en la importancia del instante: «¡mira ese portón! ¡Enano!, seguí diciendo: tiene dos caras. Dos caminos convergen aquí: nadie los ha recorrido aún hasta su final. Esa larga calle hacia atrás: dura una eternidad. Y esa larga calle hacia delante - es otra eternidad. Se contraponen esos

Asséns, México: Aguilar, 1991, vol. IV, p. 791. El subrayado es mío.

${ }^{52}$ Gentili, C., Nietzsche, tr. B. Rabadán y J.L. Serrano, Madrid: Biblioteca Nueva, 2004, p. 333.

${ }^{53}$ Za p. 435. Andrés Sánchez pascual hace constar en una nota que la afirmación de Nietzsche: «¡tú me agradas, felicidad! ¡Sus! ¡Instantes!», es una variación de la frase de Fausto: «y le diré al instante: ¡Detente, eres tan bello!», con lo que se muestra que el propio Nietzsche es consciente de que su propuesta del eterno retorno tiene uno de sus contrapuntos en el Fausto 
caminos; chocan derechamente de cabeza: - Y aquí, en este portón [Thorweg], es donde convergen. El nombre del portón está escrito arriba: 'Instante' [Augenblick] $\gg^{54}$.

El tiempo del eterno retorno es pues circular, existiendo una eternidad antes y después del instante en el que se plantea la posibilidad de la eterna repetición. Repetición que lo es de todo, no sólo de los placeres sino también de los dolores, es, decir sí o no a la propia vida en su conjunto, porque todo ello es la vida propia. El asumir incluso los momentos desagradables de la vida, es lo que según Carlo Gentili se pone de manifiesto cuando el enano que aparece en el Zaratustra muerde a la serpiente que previamente le ha mordido a él en la garganta, así es como se mitiga el dolor, aunque no como se elimina, ya que no hay forma de eliminarlo, como tampoco hay otra manera de liberarse de la mordedura de la serpiente; y es entonces, cuando: «¿quién es el pastor a quien la serpiente se le introdujo en la garganta? ¿Quién es el hombre a quien todas las cosas más pesadas, más negras, se le introducirán así en la garganta? - Pero el pastor mordió, tal como se le aconsejó mi grito; ¡dio un buen mordisco! Lejos de sí escupió la cabeza de la serpiente -: y se puso en pie de un salto. - Ya no pastor, ya no hombre, - ¡un transfigurado, iluminado, que reía! ¿Nunca antes en la tierra había reído hombre alguno como él rió» ${ }^{55}$.

Este ser humano transfigurado es el Übermensch que muerde a la propia vida en todo sus aspectos, e introduce de este modo, dentro de sí, «la verdad auténtica del eterno retorno» ${ }^{56}$. No más espíritu de venganza. Sí incluso a la verdad amarga, porque esa verdad es suya, y además: «Así lo quise» ${ }^{57}$. Este así lo quise, es lo que permite al Übermensch soportar los dolores que trae consigo la vida, es lo que permite, en términos de Sergio Givone, hablar de un pantragicismo $^{58}$ en Nietzsche, que hace imposible la parálisis y la resignación ante el dolor, al mismo tiempo que posibilita esa risa ${ }^{59}$ que convierte en digna

de Goethe.

${ }^{54}$ Ibid., p. 230.

${ }^{55}$ Ibid., p. 232.

${ }^{56}$ Gentili, C., op. cit., p. 339.

${ }^{57} \mathrm{Za}$, p. 209.

58 «Lo trágico nietzscheano, pura y gozosa transparencia de lo negativo, lleva a su culminación aquel pantagricismo que amenazaba el horizonte romántico, de Wackenroder a Hölderlin, como una estrella fatal» Givone, S., Historia de la estética, tr. M. García Lozano, Madrid: Tecnos, 1999. p. 98.

59 «Pero el placer estético de lo trágico se manifiesta también como capacidad de reír [el autor define la risa como 'música sin palabras creada para expresar la alegría y para mofarse de todo el teatro de la vida'], puesto que lo verdaderamente importante es la emancipación de la vida moral y religiosa de la propia tragedia para poder disfrutar de ella como de un espectáculo en el que desaparezca toda compasión o temor» Santiago Guervós, L., Arte y poder. Aproximación a la estética de Nietzsche, Madrid: Trotta, 2004, p. 531. El mismo autor también comenta el texto de Nietzsche del pastor que muerde la serpiente, y de su risa dice lo siguiente: «la redención y superación del hombre ya no es entonces posible ni a través de la religión, ni 
levedad esa roca que es la insoportable pesadez del ser, que arrastra ese Sísifo dichoso que promete una y otra vez serle fiel a la tierra en la que vive. Del mismo modo, Schlegel le promete serle fiel a la capacidad de seguir creando sin pretender hallar el paraíso clásico de la obra definitiva y perfecta, sino serle fiel al continuo retorno de la creación artística sobre las diferentes obras que realiza, lo que convierte su retornante vida en la obra de arte total, tal y como se pone de manifiesto, según Schlegel, a través de la crítica de arte.

De ahí, que el eterno retorno de lo idéntico en Nietzsche haya de ser entendido también como una postura anticristiana, ya que es una clara alternativa a la promesa cristiana del paraíso, al igual que el eterno retorno de lo diferente en Schlegel ha de ser entendido como una postura anticlasicista, ya que renuncia a la posibilidad de hallar una obra de arte armónica y perfecta liberada definitivamente de la escisión, debido a que la escisión es considerada -al igual que en Hölderlin- como permanente. Volviendo a Nietzsche, e insistiendo en que el eterno retorno de lo idéntico supone una alternativa a la promesa cristiana del paraíso, hay que decir que: en primer lugar, en la propuesta de Nietzsche se promete la repetición de la propia vida en su integridad y en su identidad, así se logra serle fiel ${ }^{60}$ a la vida; a diferencia de la promesa cristiana del paraíso en que se promete otra vida diferente y eterna a cambio de guiar la vida terrenal por el credo cristiano, lo que es entendido, por el pensador alemán, como una renuncia a la propia vida e infidelidad a la misma, ya que se desea otra vida diferente, en definitiva, y valga la vulgaridad, es ponerle los 'cuernos' a la vida terrenal con la vida celestial. En segundo lugar, como ya se ha comentado, en el eterno retorno, se da una visión circular del tiempo, cada instante es un fin en sí mimo, con lo que no se hipoteca unos instantes ${ }^{61}$ por otros aparentemente más importantes, ya que todos los instantes se repetirán eternamente; mientras que el cristianismo posee una visión del tiempo lineal, de manera que unos

a través del arte trágico, sino por la fuerza de la ligereza de la risa que eleva el espíritu hacia lo más alto, hacia esa 'sabiduría del pájaro', que enseña Zaratustra. Se trata de esa altura que ha neutralizado todas las contradicciones, las oposiciones entre ser y apariencia, necesidad y contingencia, superficial y profundo» ibid., p. 548.

${ }^{60}$ «La experiencia estética es, sobre todo, experiencia de lo trágico, porque, a la vez que muestra la ficción de las consolaciones ultraterrenales y destruye los arquetipos, normas y fundamentos que consuelan, devuelve al hombre a la posibilidad de vivir la vida en la alegría y el dolor por la que la vida es, destruyendo el filtro deformante de las justificaciones religiosas y científicas, en un nuevo espíritu de 'fidelidad a la tierra'» Givone, S., op. cit., p. 94.

${ }^{61}$ George Bataille, en su obra Sobre Nietzsche. Voluntad de suerte, tr. F. Savater, Madrid: Taurus, 1989, pp. 26-27; no ve exenta de problemas la propuesta del eterno retorno, ya que al eliminar de cada instante las metas para convertirlos en fines en sí mismos acaba vaciando de motivos cada instante, acaba desmotivando la vida al convertirla en un sin sentido, acaba haciendo del ser humano un individuo que tiene que elegir entre la soledad del 'desierto' de los instantes inmotivados sin metas (consecuencia y/o causa de responder sí al eterno retorno) o la 'mutilación' de los instantes motivados gracias a una teleología que da sentido racional a la vida 
instantes se pueden convertir en meros medios para otros instantes de cuya vivencia (ya sea en esta vida o en otra) se obtiene la justificación moral del dolor que pudiera haberse padecido anteriormente. En tercer lugar, en el eterno retorno el propio ser humano es el juez de su vida, ya que es él mediante su querer, su voluntad creadora de verdad (perspectivismo), el que decide si acepta repetirla, obteniendo su fuerza gracias a la vivencia de un instante por el que merece la pena haber nacido; en cambio, en la promesa del paraíso es otro ser, en este caso Dios, el que decide qué ser humano merece la salvación y quién la condena, de manera que la verdad, como ya postuló la filosofía moderna de Descartes, obtiene en última instancia su garantía en Dios. Y finalmente, si en el eterno retorno 'el demonio' no cumple lo prometido, es decir, si la vida no se repite, el ser humano al haber vivido la vida 'como si' fuera a repetirse ha logrado darle un valor inmanente y querido a su propia existencia; mientras que si es 'Dios' quién no cumple la promesa del paraíso, entonces el ser humano habrá, en cierto sentido, 'renunciado' a decidir como quiere dirigir su vida, por la promesa no cumplida de una vida mejor, convirtiendo su vida en un medio para nada.

Gentili, apoyándose en Löwith ${ }^{62}$-aunque llegando a conclusiones claramente diferentes de éste-, profundiza en el anticristianismo del eterno retorno, y defiende que es precisamente este anticristianismo lo que posibilita que con el eterno retorno se realice plenamente el anuncio nietzscheano de la muerte de Dios, y así darle sentido a la propuesta estética de la existencia de la transmutación de los valores presente en la filosofía nietzscheana y realizada por el Übermensch: «[el anticristianismo del eterno retorno] es el cuestionamiento de la modernidad misma, la negación del progresus ad infinitum de la historia, la denuncia de la solidaridad entre la concepción moderna de la historia y la concepción cristiana de la Heilsgeschichte y el fin de los tiempos. El hecho de que el tiempo no tenga fin y que retorne eternamente, que la historia no tolere un juicio final ni sea el lugar en el que está llamado a manifestarse el 'reino de Dios' es la premisa que lleva la muerte del propio Dios a su definitiva consumación, algo con lo que el aforismo 125 de La ciencia jovial no había pagado sus deudas» ${ }^{63}$.

(consecuencia y/o causa al responder negativamente al eterno retorno).

${ }^{62}$ «Nietzsche pensaba en sistema de ideas, cuyo comienzo se hallaba en la muerte de Dios; en el centro, estaba el nihilismo, debido a ese acontecimiento, y en el término se encontraba la autosuperación del mismo, mediante el eterno retorno» Löwith, K., Von Hegel zu Nietzsche, en Sämtliche Schriften, vol. IV, pp. 238ss. Hay traducción castellana de Emilio Estiú, De Hegel a Nietzsche, Buenos Aires: Sudamericana, 1968.

${ }^{63}$ Gentili, C., op. cit., p. 345. El autor mantiene que en La gaya ciencia Nietzsche aún no ha podido desarrollar todo el poder de transformación que posee el anuncio de la muerte de Dios, ya que la sombra de Dios es demasiado alargada como para liberarse de él, a pesar del anunciado funeral divino, y el propio Nietzsche es consciente de ello: «Dios ha muerto; pero, siendo los hombres lo que son, habrá acaso aún por espacio de milenios cuevas donde se 
$\mathrm{Al}$ repetirse en el eterno retorno de lo idéntico todo, incluso el instante donde se decide si aceptar la propuesta de ese demonio (que recuerda a la hipótesis del genio maligno que muta en demonio nietzscheano para recordar que el círculo cartesiano no se supera de un modo tan edificante como pretende ese 'tahúr' de la duda llamado 'Des-cartes'), y por supuesto, y esto es fundamental, la presencia y la muerte de Dios, se elimina cualquier trascendencia respecto a la revelación de Dios en el curso de la historia capaz de dividir la historia en dos, ya que la historia ahora es cíclica, eterna e inalterable, con lo que cada instante tiene el mismo valor, y, por tanto, no hay lugar para una ruptura del tiempo. La repetición de la muerte de Dios no sólo libera al ser humano del poder de la presencia del ser perfecto, sino también del poder de la sombra de su muerte (nihilismo incompleto), ya que no tiene el poder, ni en vida ni a su muerte, de cambiar la historia, ni al ser humano que en ella habita, y, en definitiva, termina por convertir al ser humano en Übermensch y al Dios cristiano en un simulacro. ${ }^{64}$

Por consiguiente, el eterno retorno de lo idéntico es lo que permite realizar por saturación (que no por suturación) ${ }^{65}$ la plena muerte de Dios y del ser humano, para dar entrada al Übermensch, y así pasar de un nihilismo incompleto o pasivo a un nihilismo completo o activo, en el que el paraíso cristiano pierde su interés y ya no son necesarias celebrar nuevas misas en honor del difunto antaño 'soberano' del universo, convertido ahora en simulacro. ${ }^{66}$ ¿ Y qué decir

muestre su sombra. - ¡Y nosotros - tendremos que vencer también a su sombra!» GC p. 147.

${ }^{64}$ « Cómo eliminar definitivamente esta presencia si no pensando que ese Dios, su presencia y su muerte, podría volver nuevamente e infinitas veces; es decir, reduciendo al Dios cristiano a un simulacro, a un ídolo, a la naturaleza de los dioses paganos; reinterpretando la dimensión teológica del único Dios cristiano a través del carácter cíclico de la mitología? La 'muerte de Dios', el estadio incompleto del nihilismo, se produce gracias a la asunción del punto de vista del eterno retorno, del nihilismo completo» Gentili, C., op. cit., p. 347.

${ }^{65}$ Para profundizar en las diferencias entre 'suturación', los intentos de superar la escisión moderna por medio del establecimiento de una pretendida armonía libre de escisiones, y 'saturación', los intentos de algunos románticos (como Hölderlin y Schlegel) de vivir en, de, y, por la escisión, ya que se considera que ésta es permanente al individuo y a la sociedad, me remito a mi tesis doctoral: «Consumaciones de la Modernidad: Hermenéutica e ironía desde el Idealismo alemán (El caso Schlegel)».

${ }^{66}$ «El problema de la eternidad, tal y como es pensado en el eterno retorno, debía hallar el camino mediante el cual Nietzsche superaría simultáneamente al 'tiempo' y al 'hombre'. Tal camino se originó con la historia del cristianismo, y Nietzsche lo caracterizó como 'autosuperación del nihilismo', el cual, a su vez, surgía de la muerte de Dios. Zaratustra es el 'vencedor de Dios y de la nada'. Sobre la base de esa conexión esencial entre la 'profecía' del eterno retorno y la del nihilismo, toda la doctrina de Nietzsche ofrece un doble aspecto, puesto que en la autosuperación del nihilismo, el 'superador y lo que se debe superar' se identifican. Son tan idénticos como la 'doble voluntad' de Zaratustra, la 'doble mirada' dionisíaca del mundo y el 'doble mundo' de Dionisos: tratase, en todos los casos, de una voluntad, de una mirada y de un mundo. La unidad entre el nihilismo y el retorno se debe a que la voluntad nietzscheana de eternidad constituye una inversión de su voluntad de la nada» Löwith, K., op. 
del pretendido mundo verdadero?: «hemos eliminado el mundo verdadero: ¿qué mundo ha quedado?, ¿acaso el aparente?... ¡No!, ¡ al eliminar el mundo verdadero hemos eliminado también el aparente! ${ }^{67}$

Si se acepta el dictamen nietzscheano de que el mundo se ha convertido en fábula, en metáfora, no entendiendo estos conceptos como una devaluación de la realidad, sino que la realidad es fábula, metáfora, entonces el modo de acceder y designar a la nueva visión de la realidad también ha de ser diferente al empleado hasta ahora. Por la misma razón de que cuando se parte de la consideración de la realidad como diferente a una fábula se requiere una razón científica, una lógica racional y un lenguaje demostrativo, cuando el mundo muta en fábula, se precisa de una razón narrativa ${ }^{68}$, una lógica inventiva ${ }^{69} \mathrm{y}$ un lenguaje metafórico ${ }^{70}$. Se transforman así los tres elementos que posee el ser humano para conocer el mundo, es decir, se transforman la razón (para comprender el mundo), el lenguaje (para hablar sobre el mundo) y la lógica (para argumentar lo comprendido por la razón y lo comunicado por el lenguaje) al transformarse el mundo en fábula.

Este cambio de la visión del mundo y de los modos de acceder a él, es lo que posibilita una 'nueva' relación entre el ser humano y el mundo, no la basada en unos conceptos que no son reconocidos como metáforas y que desde los que se aspira a una verdad no retórica que desviste al mundo de sus misterios, sino aquella que se sustenta en invenciones consideradas como tales, en metáforas

cit., vol. IV, p. 239.

${ }^{67} \mathrm{CI}$ «Cómo el 'mundo verdadero’ acabó convirtiéndose en fábula», p. 52.

${ }_{68}$ Todo proyecto que aspire al absoluto no puede ser expuesto mediante una razón científico-técnica que busca la veracidad y la verosimilitud, sino a través de una razón narrativa (posee verosimilitud, pero no veracidad unívoca, aunque sí 'veracidad de perspectivas': nunca se alcanza, ni se pretende, conclusiones finales) sino el proceso mismo en el que se narra la aspiración hacia el absoluto y su inevitable fracaso, aunque este calificativo, el de fracaso, sólo puede ser dado por una razón científica, pero nunca por una narrativa que lo caracterizaría como la finitud propia de un humano triunfo.

${ }^{69}$ Ernesto Garssí establece la diferencia entre la lógica racional y la lógica inventiva del siguiente modo: «la lógica racional afirma la necesidad de 'fundar' la unidad de sujeto y predicado en premisas que tendrían carácter universal y necesario. Por consiguiente, el problema fundamental de tal lógica es la 'demostración', o sea, el poder mostrar que la 'relación', la ‘conexión' de un sujeto con un predicado está fundada. [...] Por su parte, la ‘lógica inventiva' (como la lógica racional) debe no obstante recurrir a los 'conceptos', pero éstos [...] no pueden 'com-prender' lo real en función de un proceso deductivo, sino en función de un acto inmediato, esto es, [...] concepto metafórico» Grassi, E., «¿Preeminencia del lenguaje racional o del lenguaje metafórico? La tradición humanística», en Sevilla Fernández, J.M. - Barrios Casares, M. (eds), Metáfora y discurso filosófico, Madrid: Tecnos, 2000, pp. 39 y 41.

${ }^{70}$ «Si ya hemos de reconocer que no podemos esperar de la ciencia la verdad, querríamos saber al menos por qué motivo queríamos saber algo cuyo saber va ligado a la desilusión. En este sentido las metáforas son fósiles guía de un estrato arcaico del proceso de la curiosidad teórica; el hecho de que no haya retorno a la plenitud de sus estimulaciones y expectativas de verdad no quiere decir que sea anacrónico» Blumenberg, H., Naufragio con espectador, ed. J. 
reconocidas como metáforas. Reconocidas así tales invenciones, éstas juegan un doble papel primordial: en primer lugar, son necesarias, como ya se ha comentado, para una mejor correspondencia con un mundo que también se ha 'desvelado' (verdad en griego es alethēia, 'desvelamiento') como fábula, y en segundo lugar, porque las metáforas -como se ha mostrado a lo largo de la historia con las metáforas de la conciencia, del amor, en definitiva, de todo lo que no puede quedar reducido exclusivamente al mundo fenoménico, aunque la mayoría de las veces no asumidas como tales, tienen un claro valor epistémico. Por este doble motivo son válidas para intentar conocer poéticamente (el mundo como un texto que nos interpela a que sea interpretado) y retóricamente el mundo, un mundo que va más allá de lo fenoménico y del que se asume su condición de metafórico, de poético, de retórico.

Es así como el mundo se ha convertido en fábula y reina el perspectivismo de la retórica, y entonces, parafraseando a Nietzsche: ¿qué ha quedado entonces?, ¿Acaso la pura retórica como algo devaluado?... ¡No!, ¡al eliminar la verdad no retórica hemos eliminado también la no verdad de la retórica!

Y todo ello gracias a la propuesta del eterno retorno, la cual tiene el mismo valor, o incluso más, si ella también pasa a ser considerada una fábula, un simulacro $^{71}$. Este cambio de 'paradigma' en el que se abre de par en par las puertas de la casa de la modernidad para dar entrada al nihilismo, que comienza a realizarse en el romanticismo, tiene en Nietzsche su complementador y se prolonga en el pensamiento contemporáneo a través de las diversas inflexiones hermenéuticas de Blumenberg y Grassi, entre otros.

En definitiva, cabe afirmar que ha sido desde la propia razón científica, con su lenguaje demostrativo y con su razón lógica (lógica racional), desde donde el mundo, a los ojos de Schlegel, 'pierde su encanto', pero también ha sido la razón científica ilustrada, a pesar de sus intenciones, la artífice, a los ojos de Nietzsche (el exceso de racionalidad [científica] ha acabado con la racionalidad [científica]) de la progresiva conversión del mundo en fábula. La ironía romántica con su denuncia del desencatamiento del mundo, llevado a cabo por el afán ilustrador de la razón científica, y especialmente con su proyecto de futuro encantamiento, y la ironización romántica, proseguida por Nietzsche en su doctrina del eterno retorno, pueden ser leídas desde la actualidad como contribución a la tarea de vivir sin nostalgia ni conformismo en un mundo convertido en fábula, de reencantar un mundo que de nuevo se

Vigil, Madrid: Visor, 1995, p. 98. El subrayado es mío.

${ }^{71}$ «Si estas representaciones nos son hostiles, ¡por qué cedemos a ellas?... ¡Vengan los hermanos simulacros! Seamos los impostores y los embellecedores de la humanidad! -de hecho, esto es lo que un filósofo propiamente es» VP, citado por Fernando Savater en Idea de Nietzsche, p. 84. Savater resume del siguiente modo el papel que desempeña el simulacro en la filosofía nietzscheana: «Por medio de simulacros y metáforas huye el filósofo politeísta del cepo del monoteísmo, reinvierte el predominio de la verdad sobre la vida y utiliza finalmente la gran 
percibe como ausente de encanto. Para los románticos, el desencantamiento venía dado por el excesivo afán de verdad de la razón ilustrada, que, a fuerza de explicar el mundo, terminaba desposeyéndolo de su intrínseco misterio originario. En la actualidad, y una vez destacada la influencia de Nietzsche en el pensamiento contemporáneo, el desencantamiento viene dado por el aún excesivo afán de certezas de una razón reactivamente nihilista, que no encuentra su lugar en un mundo vacío de verdades, que no encuentra su lugar, ni su tiempo, en el eterno retorno de un mundo que se muestra como humano, demasiado humano. 